\title{
Results of a major ambulatory oral surgery program using general inhalational anesthesia on disabled patients
}

\author{
M. Cortiñas-Saenz ${ }^{1}$, Llanos Martínez-Gomez ${ }^{2}$, Manuel Roncero-Goig ${ }^{3}$, Úrsula Saez-Cuesta ${ }^{4}$, Marisa Iba- \\ rra-Martin ${ }^{5}$
}

${ }^{1}$ FEA Anestesiología y Reanimación Hospital Torrecárdenas de Almería

${ }^{2}$ Jefe de Servicio de Anestesiología y Reanimación del Complejo Hospitalario Universitario de Albacete

${ }^{3}$ Estomatólogo. Coordinador USBD-Discapacitados de la GAP de Albacete

${ }^{4}$ Odontóloga. USBD-Discapacitados de la GAP de Albacete

${ }^{5}$ Jefe de Sección de Anestesiología y Reanimación del Complejo Hospitalario Universitario de Albacete

Correspondence:

C/La Marina $n$ 2, Bloque 5, 1-A.

04007 Almería, Spain,

stl967523977@wanadoo.es

Received: 25/11/2008

Accepted: 16/02/2009

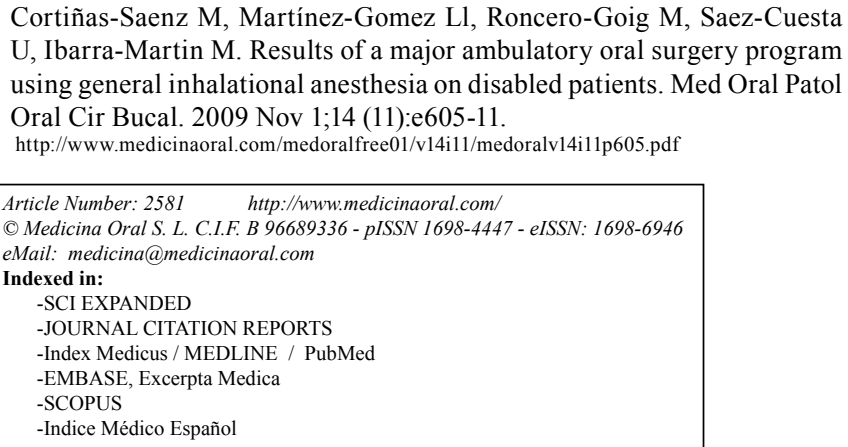

\begin{abstract}
Objectives: To assess the demographic characteristics and comorbidities of the group to be studied, as well as various quality indicators of a Major Ambulatory Surgery (MAS) program. Quantification of the surgical-anesthetic incidents. Study design: We aimed to perform a retrospective and descriptive analysis of disabled patients who had received oral ambulatory surgery under general anesthesia. Data obtained from the clinical history and telephone interview included the demographic characteristics, socioeconomic status, previous dental history, cause of the mental disability, degree of mental retardation, comorbidity measured according to the scale of the American Society of Anesthesiologists (ASA), anesthesia or preoperative surgical treatments, level of analgesia, length of stay, incidents in the Resuscitation Ward, the rate of substitution, suspensions, patients admitted, complications and the degree of patient satisfaction. Results: We included 112 oral surgery procedures performed on disabled patients who were treated under general inhalational anesthesia as part of MAS during the years 2006-2007. During this period, 577 restorations, 413 extractions, 179 sealants, 102 pulpectomies, 22 root canal treatments, 17 gingivectomies and 3 frenectomies were performed. A total of $75 \%$ (78 cases) of the patients had coexisting medical pathology. The average surgery time per patient was $72.69 \pm 29.78$ minutes. The rate of replacement was $100 \%$. The rate of suspension was $1.92 \%$. The percentage of patients readmitted was $1.92 \%$,due to significant bleeding in the mouth, which did not require treatment and the patients were discharged from hospital 24 hours after being admitted. The rate of patients who required re-hospitalization was 3.84\%. Conclusions: The MAS performed in this group, despite being on patients with high comorbidity resulted in only a low number of medical incidents reported.
\end{abstract}

Key words: Mental retardation, Down Syndrome, dental caries, ingival, anesthesia, Ketamine. 


\section{Introduction}

The mentally disabled population represents a group with a high incidence of oral disease caused by factors that are specific to the disability itself: high incidence of cavities, periodontal disease, lack of hygiene habits, cariogenic diets, drug treatments, etc. In the current state of well-being, there is a growing social demand for dental treatment for this group, which sometimes requires different techniques of general anesthesia in order for the procedure to be properly carried out. To meet this demand, the Castilla la Mancha Health Service (SESCAM) developed a Dental Care Plan for the Disabled.

The aim of the different dental care programs is to treat oral disease in these patients. In cases in which such treatment cannot be carried out at the dental office, it must be performed under general anesthesia. The fluent communication between the departments of anesthesiology and odontostomatology is important so as to avoid unnecessary surgical treatments (1). Acceptance of future dental treatments is influenced by prior experience and an appropriate pharmacological amnesia of the different processes (2). In this context, it is important to create clinical pathways for patients with special needs who are going to be treated while under anesthesia and / or conscious sedation, as well as various prevention programs. Typically, postoperative complications from oral surgery are estimated to be approximately $7 \%$ (3), with a significant number of prolonged awakenings after general anesthesia. However, thanks to technological and pharmacologic advances, these numbers have been dramatically reduced, making it possible to use general anesthesia in various Major Ambulatory Surgery (MAS) programs. The MAS in these types of procedures involves minimal alteration of the familiar and social environment of these patients, with a low number of anesthetic-surgical incidences.

The aim of our study was to learn about the demographic and comorbidity characteristics of the disabled population treated in a public non-profit public hospital, as well as the results and anesthetic and surgical incidences of a general inhalational anesthesia protocol used in MAS.

\section{Material and Methods}

This involves a retrospective observational study conducted in a public hospital during the period between February 15, 2006 to December 31, 2007, following the adoption of Decree 273/2004 of November 9th, regarding the provision of dental care to the population of Castilla la Mancha, including disabled persons who have certain medical conditions, and Decree 34/2006 of March 28th, which is a modification of the previous law and includes disabled people with no age limit (4.5). Although the study design is retrospective, the informa- tion about the surgical procedure of each one of the subjects was generated before presenting the research; the observation is prospective in terms of analysis, as the population studied comprises $100 \%$ of the patients of the group. The Department of Oral Health for Disabled Persons (known by its Spanish acronym as USBD-D) consists of odonto-stomatologists, hygienists, anesthesiologists and nurses. The patients included in the study were all operated under the MAS program. The surgical activity consisted of a weekly surgery. The operating room has standard monitoring (electrocardiogram, noninvasive and invasive blood pressure, pulse, Bispectral Index), respirator with gas analyzer, gas extraction and aspiration systems. The scheduling of the waiting list and weekly surgery is handled by the odonto-stomatologists of the department.

The preoperative study in all of the patients consisted of an evaluation by means of clinical history and amanesis of the airway for screening of a potentially difficult airway, as well as evaluation of the respiratory, cardiac and neurological functions. The laboratory tests performed included: hemogram, coagulation and biochemical testing. A chest x-ray and electrocardiogram were performed as prescribed by the anesthesiologist. The informed consent for administering general anesthesia was signed by the patient's legal guardian. In the cases where it was necessary, antibiotic prophylaxis was indicated for bacterial endocarditis, and anticomicial treatment was used in patients with convulsive disorder. Upon admission to the ward, the disabled patient was given a face-mask in order that he/she may become familiar with this device. Two dressings were placed with EMLA cream for subsequent venipuncture and the patient's guardians were given a syringe for administering the oral medication. The pre-anesthetic oral medication in aggressive patients with no history of epilepsy, heart disease or obstructive sleep apnea, consisted of midazolam 0.3-0.6 mg/kg, ketamine 3-6 mg/kg, and ibuprofen $0.6 \mathrm{mg} / \mathrm{kg}$. For the cases in which it was not possible to administer the medication orally, midazolam $0.05 \mathrm{mg} / \mathrm{kg}$, ketamine $1.5 \mathrm{mg} / \mathrm{kg}$ and atropine 0.3 $\mathrm{mg} / \mathrm{kg}$ were administered intramuscularly. Patients who had a contraindication for the use of benzodiazepines or ketamine as pre-medication, were given ibuprofen 0.6 $\mathrm{mg} / \mathrm{kg}$ and hydroxicine $0.6 \mathrm{mg} / \mathrm{kg}$ orally.

The anesthetic technique in all of the cases was general anesthesia by inhalation induction with sevoflurane (CAM 6-8\%) and 100\% oxygen until an appropriate level of anesthetic depth was achieved, at which point, we proceeded to channel a peripheral path, placing surgical patties with epinephrine (topical anesthesia) in the more permeable nostril. We then administered atropine, fentanyl at $1-1.5 \mu \mathrm{cg} / \mathrm{kg}$ intravenously, under direct laryngoscopy or insertion of the laryngeal mask, without using neuromuscular relaxants. Sometimes, propofol 
was also administered in order to improve endotracheal intubation conditions. Finally, we placed the oropharyngeal tamponade. Intubation was only performed in conditions of apnea when we were certain that there was not a potentially difficult airway. The anesthetic maintenance was carried out with a dosage of sevoflurane, oxygen-air and remifentanyl 0.05- $0.20 \mu \mathrm{gr} / \mathrm{kr} / \mathrm{min}$ in order to maintain a Bispectral Index (BIS) between 45 and 55. At the discretion of the anesthesiologist, the patient was gassed in a controlled method or by spontaneous breathing. Provided there was not any contraindication, post-intubation medication consisted of antibiotic prophylaxis (ampicillin $50 \mathrm{mg} / \mathrm{kg}$ ), antiemetic prophylaxis (ondasentron $0.1 \mathrm{mg} / \mathrm{kg}$ ), gastric prophylaxis (ranitidine $1.5 \mathrm{mg} / \mathrm{kg}$ ), preemptive analgesia (desketoprofen 0.5 $\mathrm{mg} / \mathrm{kg}$ ) and corticoids (dexamethasone $0.15 \mathrm{mg} / \mathrm{kg}$ ). Blood pressure was monitored non-invasively, and an electrocardiogram, arterial saturation by pulsimetry, and analysis of gases were performed in order to measure the percentage of halogenated anesthetic and concentration of $\mathrm{CO}_{2}$ inhaled at the end of exhalation, and levels of hypnosis using BIS monitor. Fluid therapy was with glucosaline serum $10 \mathrm{~mL} / \mathrm{kg}$. The pressure points were cushioned and the corneas were protected. Local or truncular anesthesia was performed by the dentist before beginning the surgical procedure. For cases in which dental extractions were performed, the patient was given paracetamol $15 \mathrm{mg} / \mathrm{kg}$ or ketorolac $0.5 \mathrm{mg} / \mathrm{kg}$, once the procedure was finished.

The first phase of postoperative analysis was performed at the Post-Anesthesia Recovery Unit (PACU), and then in the rehabilitation wards on site. After meeting the general discharge criteria by means of modified Aldrete test, the patient went home. For all patients, the standard home analgesia consisted of a combination of paracetamol and ibuprofen, along with gastric protection with ranitidine, except in the case of relative or absolute contraindications to the use of any of the active ingredients. Patients were given an antibiotic treatment of amoxicillin-clavulanate for six days. Twenty four hours after the hospital discharge, we called the patient's home in order to follow up on the progress of the patient. The patient and family completed a satisfaction survey.

Based on each clinical history and phone interview, we obtained the demographic characteristics (age, sex, weight), socioeconomic status, previous dental history and dental treatments performed, whether public or private, etiological cause of the mental disability, degree of mental retardation, associated comorbidity quantified by the scale of the American Society of Anesthesiologists (ASA), assessment of the airway using the Mallampati classification, method of control of the airway, use of muscle relaxants and ketamine, preoperative and intraoperative anesthetic or surgical incidents, assessment of the level of analgesia using the visual analogue scale (VAS), length of stay and incidences in APPU, the replacement rate, the rate of suspensions, the rate or number of hospitalizations, any complications that occurred and the rate of satisfaction.

The replacement rate is the percentage of interventions carried out as MAS with regard to the total number of dental surgery procedures performed at the center. The rate of hospitalization corresponds to patients who are scheduled for MAS and end up requiring unplanned hospitalization. The rate of suspensions corresponds to those interventions not performed on the day of the scheduled procedure. The rate of re-hospitalizations corresponds to patients who are discharged from the hospital and end up being hospitalized again due to a complication that arises within a period of 7 days after surgery.

In the gathering and handling of information, we adhered to the rules regarding the discretion and respect for patient privacy, according to the Rules of the Ethics Committee of our hospital. Because the patients were treated in our MAS department, and because identifying information is not published, formal approval by the Ethics Committee was not required.

The description of the qualitative data was conducted in the form of absolute frequencies and percentages. Quantitative data were described using the mean and standard deviation. A descriptive and univariant analysis was carried out with the tests of the $t$ for Student (quantitative variables) or $\mathrm{chi}^{2}$ (qualitative variables). The values for $p<0.05$ were considered statistically significant. The data was processed using the program Stata release 7 (Stata Corp., College Station, TX).

\section{Results}

During the study period, dental care was provided at the Department of Oral Health for Disabled Persons for a total of 346 patients. Of these patients, $61 \%$ received treatment at the dental clinic of the health center, whereas the rest of the patients required treatment under general anesthesia or are on the waiting list for surgery.

We gathered 112 oral surgery procedures that had been performed on disabled patients who were operated under general inhalational anesthesia as part of major ambulatory surgery. Of these cases, 8 were excluded due to incomplete information in the medical history. During this period, 577 fillings, 413 extractions, 179 sealants, 102 tartrectomies, 22 root canals, 17 gingivectomies and 3 frenectomies were performed. The most frequent pathology was cavities in $81 \%$ of patients, with an average of $7.3 \pm 4.3$ cavities and a range of 1 to 14 cavities. Cleaning of the dental plaque was the second most common pathology. The most frequent course of treatment is conservative as opposed to extractions.

The average age of the patients was $24.07 \pm 13.17$ years old, with a range from 2 to 64 years old. Pediatric pa- 
Table 1. Demographic characteristics of the population studied.

\begin{tabular}{|c|c|c|}
\hline VARLABLES & No. Cases & Percentage \\
\hline Number of patients & 104 & $100 \%$ \\
\hline Age (yeas) & $24.07+13.17$ & \\
\hline $\begin{array}{l}\text { Sex } \\
\text { - Males } \\
\text { - Females }\end{array}$ & $\begin{array}{l}66 \\
38\end{array}$ & $\begin{array}{l}63.46 \% \\
36.54 \%\end{array}$ \\
\hline $\begin{array}{l}\text { Distance from home ( } \mathrm{Km}) \text { : } \\
\text { - Less than } 5 \mathrm{Km} \\
\text { - Betueen } 5-90 \mathrm{Km} \\
\text { - Betueen } 91-150 \mathrm{Km} \\
\text { - Hore than } 150 \mathrm{Km}\end{array}$ & $\begin{array}{l}33 \\
28 \\
23 \\
20\end{array}$ & $\begin{array}{l}31.73 \% \\
26.92 \% \\
22.11 \% \\
19.23 \%\end{array}$ \\
\hline $\begin{array}{l}\text { ASA Classification: } \\
\text { •I } \\
\text { •II } \\
\text { • III } \\
\text { - IV }\end{array}$ & $\begin{array}{c}6 \\
61 \\
35 \\
2\end{array}$ & $\begin{array}{c}5.77 \% \\
58.65 \% \\
33.65 \% \\
192 \%\end{array}$ \\
\hline $\begin{array}{l}\text { Mallanpati Classification: } \\
\text { - Easyintubation } \\
\text { - Difficult intubation } \\
\text { - Unable to evahuate }\end{array}$ & $\begin{array}{c}52 \\
6 \\
46\end{array}$ & $\begin{array}{l}50 \% \\
5.76 \% \\
44.23 \%\end{array}$ \\
\hline $\begin{array}{l}\text { Etiology of disability: } \\
\text { - Intrapartum anoxia } \\
\text { - Down Syndrome } \\
\text { - Other chnomosomopathies } \\
\text { - Severe mental retardation not affiliated } \\
\text { - Cardiorespirabry failure } \\
\text { - Autism } \\
\text { - Moderate mental retardation not affiliated } \\
\text { - Infectious causes } \\
\text { - Other }\end{array}$ & $\begin{array}{c}33 \\
12 \\
18 \\
9 \\
1 \\
9 \\
7 \\
2 \\
11 \\
2\end{array}$ & $\begin{array}{c}31.73 \% \\
11.54 \% \\
17.31 \% \\
8.65 \% \\
0.96 \% \\
8.65 \% \\
6.73 \% \\
192 \% \\
10.58 \% \\
192 \%\end{array}$ \\
\hline $\begin{array}{l}\text { Presence of Comorbilityr } \\
\text { - None } \\
\text { - One } \\
\text { - Two } \\
\text { - Three } \\
\text { - Four }\end{array}$ & $\begin{array}{c}26 \\
41 \\
25 \\
8\end{array}$ & $\begin{array}{c}25 \% \\
39.42 \% \\
24.04 \% \\
7.69 \% \\
385 \%\end{array}$ \\
\hline $\begin{array}{l}\text { Degree of mental retardation: } \\
\text { - Acute (IQ }=50) \\
\text { - Hoderate }(\mathrm{IQ} 35-49) \\
\text { - Severe }(\mathrm{IQ} 20-34) \\
\text { - Deep }(\mathrm{IQ}<\mathbf{2 0})\end{array}$ & $\begin{array}{l}8 \\
35 \\
50 \\
11\end{array}$ & $\begin{array}{l}7.69 \% \\
33.65 \% \\
48.08 \% \\
10.58 \%\end{array}$ \\
\hline \multicolumn{3}{|c|}{$\begin{array}{l}\text { ASA Seals according to the American Sociey of Anesthesiob gists } \\
\text { IQ: Bntellectual Quotient }\end{array}$} \\
\hline
\end{tabular}


Table 2. Incidences that occurred in the postoperative recovery room

\begin{tabular}{|c|c|c|}
\hline COMPLICATION & No. Cases & Percentage \\
\hline $\begin{array}{l}\text { Pain: } \\
\text {-Severe (VAS >7) } \\
\text {-Moderate (VAS 4-6) } \\
\text {-Slight (VAS 1-3) }\end{array}$ & $\begin{array}{c}39 \\
0 \\
5 \\
34\end{array}$ & $\begin{array}{c}37.5 \% \\
- \\
4.8 \% \\
32.69 \%\end{array}$ \\
\hline Vomiting & 6 & $5.76 \%$ \\
\hline Bleeding & 4 & $3.84 \%$ \\
\hline Agitation & 2 & $1.92 \%$ \\
\hline $\begin{array}{l}\text { Awake for prolonged period } \\
\text { of time }\end{array}$ & 1 & $0.96 \%$ \\
\hline TOTAL & 52 & $50 \%$ \\
\hline
\end{tabular}

tients represent $27.88 \%$ of the total patient group. There is a clear predominance of males, with a proportion of 1.73:1. The most frequent cause of disability was mental retardation in 41 patients (39.42\%). In $75 \%$ ( 78 cases) of the patients treated, they presented a coexisting medical condition and the number of prescribed medications that they were taking was $2.13 \pm 1.79$ per disabled person. In $40.38 \%$ of the patients (42 cases), a history of epilepsy was observed in the pre-anesthetic history. The presence of structural heart disease was found in $8.65 \%$ of the patients ( 9 cases).We did not find any statistically significant differences between the onset of complications and the existence of a previous history of heart disease and epilepsy. In $66.35 \%$ of the patients (69 cases), there was no history of surgery. During the preparation of the patient in pre-surgery, there were 2 minor incidences of the disabled patient attacking the nurses. Demographic variables such as age, sex, ASA, comorbidity, distance from home to the hospital, etiology and degree of mental retardation are shown in Table 1.

General inhalational anesthesia was performed without the use of muscle relaxants in $97.12 \%$ of the patients (101 cases), and nasotracheal intubation was used for 89 patients. The number of difficult intubations was described in two cases, which were resolved by placement of a laryngeal mask on one occasion, and in another by replacing orotracheal intubation with nasotracheal intubation. The total number of dental procedures performed was 1291, with surgery time averaging $72.69 \pm$
29.78 minutes per patient. The average length of stay in the Ambulatory Surgery Unit was $140.91 \pm 29.78$ minutes. The main incidences that occurred in the postoperative awakening room are reflected in Table 2.

The rate of replacement of the unit was $100 \%$ during the study period. The suspension rate was $1.92 \%$ ( 2 cases), one case due to the coexistence of blockage in the upper respiratory tract and the other due to non-attendance of the patient on the date of scheduled surgery. The rate of hospitalization was $1.92 \%$ ( 2 cases) and in both cases, it was due to significant bleeding from the mouth. However, neither patient required special treatment and both patients were discharged from hospital within 24 hours of being admitted; in both cases, it is related to gingivectomies. The rate of re-hospitalizations was $3.84 \%$ (4 cases) and the reasons that prompted the medical attention were fever that was probably due to dental extraction, retention of urine, drowsiness that was likely due to prescribed drugs, and an episode of psychomotor disturbance. Two hospitalizations were required, although unrelated to the surgical procedure (craniocerebral trauma and paraphimosis).

\section{Discussion}

Mental retardation affects people of all races and social class. The World Health Organization estimated the incidence to affect $3 \%$ of the world's population. In Spain, it is estimated that $15 \%$ of the population has some sort of disability, with $4-5 \%$ of the cases considered to be 
moderate-severe. There is a change in the behavior of the general population towards people with disabilities and there are health policies that emphasize the integration and inclusion of disabled persons in public and social life. Poor oral hygiene, often present in people with disabilities, has a significant impact on their quality of life. Dental problems are among the top ten causes that limit the activity of disabled people, the most common are dental cavities, tooth loss and periodontal disease (6). The percentage of patients in our department who required treatment under general anesthesia and the cause of disability support that observed by other authors (7). Consistent with the findings of Escribano et al (7), cavities and cleaning of dental plaque are the most frequent dental problems; however, in contrast, conservative treatments were more frequent than extractions in our study group.

The disabled population is entitled to receive oral health care as a part of the Public Health Service, yet this requires specialized methods in order for it to be properly implemented. Although most of the autonomous regions offer some sort of dental care for disabled persons, perhaps it can be said that the provinces of Asturias, Extremadura and Navarre are the most advanced in offering dental treatment to the disabled population (7.8). Attention to disabled persons in the Community of Castilla La Mancha currently has two dental clinics (Albacete and Ciudad Real). Except for the conservative treatment of temporary teeth and dentures, all treatments are offered without imposing any type of age limits. Before these clinics opened their doors, the only solution to the pathologies was surgery with multiple extractions. Disparities in oral health conditions and access to dental care for disabled persons have a significant epidemiological importance, as the use of private dentistry services is relatively low.

The MAS can be applied to all surgical procedures subject to be performed under general, regional or local anesthesia, or sedation, and which require minor and short-term postoperative care, allowing the patient back to return home within a few hours after the undergoing the procedure. The progressive expansion and maturity of the MAS is observed with the elimination of usual exclusion criteria, such as the distance from home, the presence of an associated pathology, certain treatments, physical and psychological defects (9). Thus, in our work we found that due to the vastness of our region, $41.34 \%$ of patients (43 patients) described their usual residence as being located more than $90 \mathrm{~km}$ from the hospital and $75 \%$ of patients (100 patients) presented associated comorbidity, not finding significant statistical differences between these variables and the rate of complications and re-hospitalizations. Several studies show that the incidence of medical and surgery complications following dental procedures performed using general anesthesia is minimal. In the classic study of Nordenram (3) carried out on 1,457 patients who underwent oral surgery, there was an incidence of bleeding reported in $0.75 \%$ of the cases, $1.78 \%$ lower than what we show in our series. In the aforementioned study, the percentage of prolonged awakenings was $0.68 \%$, while there was no such case in our group. A possible explanation may be due to technological advances and new anesthetic drugs with a more ideal pharmacokinetics. In this context we decided to start the program of the Department of Oral Health for Disabled Persons in the form of clinical surgery (not requiring hospitalization). After implementation of the MAS in all of the disabled patients of the Department of Oral Health for Disabled Persons (replacement rate of $100 \%$ ), we obtain a rate of hospitalization that is less than $2 \%$ and a rate of re-hospitalization is reported in 4 cases (3.84\%) with minimal severity. These figures show that the MAS in this group is a safe and effective surgical procedure despite being patients with high comorbidity (33.65\% of the patients were ASA III).

The families are very involved in the oral health programs of the public healthcare service, a statement consistent with the existence of a rate of $1.92 \%$ suspension and only a single case of patient not appearing for surgery at our clinic.

Postoperative nausea and vomiting (PONV) along with pain are the most frequent and significant complications associated with MAS. Both have broad repercussions because they constitute the most common medical causes of delay in discharge of the patient, as well as re-hospitalizations. In the MAS units, the incidence of PONV varies between $3.5 \%$ and $4.6 \%$ (10). In our group, the incidence is higher (5.76\%). This value may be explained by the use of inhalational anesthesia, which traditionally has been associated with an increase in PONV (11). Acute postoperative pain increases the incidence of PONV (12). Is a quality indicator in the satisfaction surveys, and its incidence is difficult to quantify, but several authors agree that it is high. We believe that the onset of moderate pain in only five cases $(4.8 \%)$ indicates that the strategy of local or troncular infiltration, along with systemic analgesia, is effective. The scientific evidence that is available today allows us to affirm that the goal of achieving an adequate postoperative analgesia comfort and PONV is only achieved with the use of analgesic techniques that are balanced or use multiple methods, which covers drugs such as paracetamol, the NSAIDs, the infiltration of the surgical wound and peripheral nerve blocks (PNB). The use of opiates increases the incidence of PONV (13). Complications of soft tissue, bone, joint and nerve tissues are also rare. In the last months of the study, ventilation with laryngeal mask was used in 8 cases without any notable incident, except that the surgical field was worsened and it 
caused discomfort to the dentist. The importance of this instrument is its use in cases where tracheal intubation is not possible, and one must remember the potential for this to occur with this group, given that in $44.23 \%$ (46 cases), it was not possible to explore during the airway during the pre-operative visit, due to lack of cooperation on the part of the patient.

The literature indicates a high prevalence of adverse events in dental practice with patients who suffer heart problems (14). We did not find any statistically significant differences in the occurrence of intra-postoperative complications in disabled patients with and without coexisting cardiac and neurological pathology, which may be explained by the use of a correct preoperative anxiolysis without ketamine, use of multimodal analgesia and in certain situations, refraining from the use of local anesthetics containing epinephrine.

Collaboration and implementation of clinical pathways between primary and specialty care in patients with disabilities who require general anesthesia may improve the results of these programs (15). The implementation of MAS, along with major advances in the field of anesthesiology, has provided adequate oral healthcare for disabled patients without altering the environment of these patients, given that when applied within this surgical method, the patients may return to their homes within a few hours of having received the treatments they need. Even so, Cumella (16) shows that in England, the prevalence of untreated cavities is still very high due to low expectations about the conditions of oral health in people with disabilities, fear of treatment and lack of interest from people responsible for taking care of them. Also consistent with those findings, in our group of pediatric patients younger than 14 years old, only $32 \%$ of children had received oral care at a private clinic at any previous time.

Health authorities must get involved in publicizing health programs, especially in the most disadvantaged sectors of the population.

\section{References}

1. Barberia E, Arenas M, Gómez B, Saavedra-Ontiveros D. An audit of paediatric dental treatments carried out under general anaesthesia in a sample of Spanish patients. Community Dent Health. 2007; $24: 55-8$.

2. Jensen B, Schröder U. Acceptance of dental care following early extractions under rectal sedation with diazepam in preschool children. Acta Odontol Scand. 1998;56:229-32.

3. Nordenram A. Postoperative complications in oral surgery. A study of cases treated during 1980. Swed Dent J. 1983;7:109-14.

4 . Decree 273/2004 of November 9th, regarding the provision of dental care to the population of Castilla-La Mancha, with ages ranging between 6 and 15 years old. Diario Oficial de Castilla la Mancha (Official Journal), November 12, 2004, No 213. p.18433-4.

5. Decree 34/2006 of March 28th, modification of Decree 273/2006. 6. Escribano Hernández A, Hernández Corral T, Ruiz-Martín E, Porteros Sánchez JA. Results of a dental care protocol for mentally handicapped patients set in a primary health care area in Spain. Med Oral Patol Oral Cir Bucal. 2007;12:E492-5.
7. Limeres Posse J, Vázquez García E, Medina Henríquez J, Tomás Carmona I, Fernández Feijoo J, Diz Dios P. Pre-assessment of severely handicapped patients suitable of dental treatment under general anesthesia. Med Oral. 2003;8:353-60.

8. Bruma M, Gallardo N, De Nova J, Mourelle M a R. Providing dental care for disabled children in the Public Health System in Spain. Med Oral 2007;12:314-319.

9. Pohl Y, Filippi A, Geiger G, Kirschner H, Boll M. Dental treatment of handicapped patients using endotracheal anesthesia. Anesth Prog. 1996;43:20-3.

10. Gupta A, Wu CL, Elkassabany N, Krug CE, Parker SD, Fleisher LA. Does the routine prophylactic use of antiemetics affect the incidence of postdischarge nausea and vomiting following ambulatory surgery?: A systematic review of randomized controlled trials. Anesthesiology. 2003;99:488-95.

11. Johannesson GP, Florén M, Lindahl SG. Sevoflurane for ENTsurgery in children. A comparison with halothane. Acta Anaesthesiol Scand. 1995;39:546-50.

12. Sakellaris G, Georgogianaki P, Astyrakaki E, Michalakis M, Dede O, Alegakis A, et al. Prevention of post-operative nausea and vomiting in children--a prospective randomized double-blind study. Acta Paediatr. 2008;97:801-4.

13. Shirakami G, Teratani Y, Segawa H, Matsuura S, Shichino T, Fukuda K. Omission of fentanyl during sevoflurane anesthesia decreases the incidences of postoperative nausea and vomiting and accelerates postanesthesia recovery in major breast cancer surgery. $\mathrm{J}$ Anesth. 2006;20:188-95.

14. Margaix Muñoz M, Jiménez Soriano Y, Poveda Roda R, Sarrión G. Cardiovascular diseases in dental practice. Practical considerations. Med Oral Patol Oral Cir Bucal. 2008;13:E296-302.

15. De Nova-García MJ, Martínez MR, Sanjuán CM, López NE, Cabaleiro EC, García YA. Program for coordinated dental care under general anaesthesia for children with special needs. Med Oral Patol Oral Cir Bucal. 2007;12:E569-75.

16. Cumella S, Ransford N, Lyons J, Burnham H. Needs for oral care among people with intellectual disability not in contact with Community Dental Services. J Intellect Disabil Res. 2000;44( Pt 1):4552. 